\title{
Water Quality Modelling of the Mekong River Basin: Climate Change and Socioeconomics Drive Flow and Nutrient Flux Changes to the Mekong Delta
}

\author{
P.G. Whitehead ${ }^{1,2}$, L. Jin ${ }^{3}$, G. Bussi' ${ }^{2}$, H.E. Voepel ${ }^{1}$, S.E. Darby ${ }^{1}$ \\ G.,Vasilopoulos ${ }^{1,7}$, R. Manley ${ }^{4}$, H. Rodda ${ }^{4}$, C. Hutton ${ }^{1}$, C. Hackney ${ }^{7}$, \\ Van Pham Dang Tri $^{5}$, and N.N. Hung ${ }^{6}$
}

${ }^{1}$ School of Geography and Environmental Science, University of Southampton, Southampton, SO17 1BJ, UK

${ }^{2}$ School of Geography and the Environment, University of Oxford, Oxford, OX1 3QY, UK

${ }^{3}$ Geology Department, State University of New York College at Cortland, Cortland, NY 13045, USA

${ }^{4}$ Water Resource Associates, Wallingford, PO Box 838, Oxon OX10 9XA, UK

${ }^{5}$ Department of Water Resources, College of Environment and Natural Resources, Research Institute for Climate Change, Can Tho University, Vietnam

${ }^{6}$ Southern Institute of Water Resources Research (SIWRR), Research Centre for Rural Infrastructure Engineering Development, 658th Vo Van Kiet avenue Dist.5 HCMC, Vietnam

${ }^{7}$ Energy and Environment Institute, University of Hull, Cottingham Road, Hull, HU6 7RX, UK

Corresponding author email: paul.whitehead@ouce.ox.ac.uk;

Tel: +44 7972805094.

\begin{abstract}
The Mekong delta is recognised as one of the world's most vulnerable mega-deltas, being subject to a range of environmental pressures including sea level rise, increasing population, and changes in flows and nutrients from its upland catchment. With changing climate and socioeconomics there is a need to assess how the Mekong catchment will be affected in terms of the delivery of water and nutrients into the delta system. Here we apply the Integrated Catchment model (INCA) to the whole Mekong River Basin to simulate flow and water quality, including nitrate, ammonia, total phosphorus and soluble reactive phosphorus. The impacts of climate change on all these variables have been assessed across 24 river reaches ranging from the Himalayas down to the delta in Vietnam. We used the UK Met Office PRECIS regionally coupled climate model to downscale precipitation and temperature to the Mekong catchment. This was accomplished using the Global Circulation Model GFDL$\mathrm{CM}$ to provide the boundary conditions under two carbon control strategies, namely representative concentration pathways (RCP) 4.5 and a RCP 8.5 scenario. The RCP 4.5 scenario represents the carbon strategy required to meet the Paris Accord, which aims to limit peak global temperatures to below a $2{ }^{\circ} \mathrm{C}$ rise while seeking to pursue options that limit temperature rise to $1.5^{\circ} \mathrm{C}$. The RCP 8.5 scenario is associated with a larger $3-4{ }^{\circ} \mathrm{C}$ rise. In
\end{abstract}


addition, we also constructed a range of socio-economic scenarios to investigate the potential impacts of changing population, atmospheric pollution, economic growth and land use change up to the 2050s. Results of INCA simulations indicate increases in mean flows of up to $24 \%$, with flood flows in the monsoon period increasing by up to $27 \%$, but with increasing periods of drought up to 2050. A shift in the timing of the monsoon is also simulated, with a 4 week advance in the onset of monsoon flows on average. Decreases in nitrogen and phosphorus concentrations occur primarily due to flow dilution, but fluxes of these nutrients also increase by $5 \%$, which reflects the changing flow, land use change and population changes.

Key Words: Mekong River, Nutrients, Modelling, Climate Change, Socioeconomic Change, Land Use Change, Vietnam Delta

\section{INTRODUCTION}

The world's deltas are highly productive agricultural regions, but most are under threat from a combination of rising sea levels and ground surface subsidence, with associated impacts on salinization and land degradation (Nicholls et al., 2016, 2015). In addition, there are longterm changes occurring in many of the river basins upstream of deltas as a result of land use and climate change, population increases, and other industrial and socioeconomic changes (Vörösmarty et al., 2010; Whitehead et al., 2015 a, b). These upstream pressures may limit the opportunities to maintain productive agriculture in delta systems through potential reductions in nutrient fluxes, altered flood regimes and changes in land surface levels.

Climate change is now confirmed as a problem of global concern (Edenhofer et al., 2014) and the Intergovernmental Panel on Climate Change (IPCC) report (2014) highlights large river basins and delta regions to be under particular threat. Although the Paris accord aims to limit the rise in global temperatures to no more than $2{ }^{\circ} \mathrm{C}$ above pre-industrial levels, while seeking to pursue options that limit the rise to $1.5^{\circ} \mathrm{C}$, at the current rate of carbon emissions a $3-4{ }^{\circ} \mathrm{C}$ rise looks more likely. Such a significant rise in temperature directly threatens the viability of the world's major deltas.

Of the world's major deltas, the Mekong Delta (MD) is one of the most vulnerable, with many poor communities being exposed to threats from floods, changing water quality and land subsidence. The Mekong River's catchment delivers vast quantities of water to the delta and large fluxes of sediments and nutrients. There have been extensive evaluations of water resources in the Mekong driven by the World Bank and the Mekong River Commission (Lu et al, 2014, Xue et al, 2012), but relatively few studies on water quality, although an extensive biophysical study was undertaken to provide empirical data and analysis (Campbell et al. 2009, Fan et al, 2015).

Studies in other large rivers systems in Asia, Africa and Europe including the Volta, Ganges, Brahmaputra, Meghna, Hooghly, Thames and the Mahanadi (Jin et al, 2015, 2018a, 2018b, Crossman et al, 2012, Whitehead et al 2012, 2015, 2018, Nicholls et al 2018) show a consistent pattern of change under the twin threats of climate and socioeconomic change. Common results from these studies are altered flow regimes, with increased flows in wet seasons and reduced flows in the dry seasons. These hydrological regime variations generate increased flood risk and extended periods of droughts, threatening catchment infrastructure and water supplies for public use and irrigation. In terms of water quality, there are also consistent patterns emerging, including the effects of reduced dilution during drought, thereby raising pollutant concentrations. The increased flushing of pollutants from both urban areas and rural agricultural areas is also exacerbated, thereby enhancing diffuse runoff of pollutants, such as nutrients, pesticides, emergent chemicals and plastics. In 
addition, temperature increases affect the reaction kinetics of soil and water biogeochemistry, altering decay rates and this, coupled with altered residence times, alters the mass balance of chemicals in the environment. Whitehead et al (2010) reviewed the impacts of climate change on water quality and all these effects impact large river systems, and are magnified as future socioeconomic changes occur. From a socioeconomic point of view, population increases play a major role, driving up effluent discharges, creating more intensive agriculture and putting pressure on the river systems. This, coupled with enhanced industrial activity, such as highly polluting urban industrial discharges from tanneries, garment manufacturing and chemical plants creates extensive pollution problems, destroying the oxygen balance and ecology of many urban rivers (Whitehead et al, 2018).

In order to consider the impacts on the Mekong, here we apply a dynamic, process-based model of flow and water quality to the entire catchment of the Mekong River system. The Integrated Catchment (INCA) suite of models (Whitehead et al, 2015 a, b, Whitehead et al,1998 a, b, Wade et al, 2002 a, b) is a dynamic process-based modelling system that accounts for the highly non-linear nature of large, complex rivers, integrating flow, water quality and ecology (Jin et al., 2018a, 2015, Whitehead et al., 2015 a, b Pathak et al, 2018). The main objectives of the study have been to evaluate the impacts of climate change and socioeconomic change on future hydrology and nutrient fluxes in the Mekong River and assess the altered fluxes entering the Vietnam Delta System. Specifically, we use the outputs from a Regional Climate Model (RCM) to downscale precipitation and temperature from a Global Circulation Model (GCM) so as to drive a flow and water quality model for the Mekong under scenarios of future climate and socioeconomic change. These socioeconomic changes include such factors as the intensification of agriculture, deforestation, rising populations and increased industrial development. Moreover, in the Mekong, there have been major developments of dams for hydropower and to support irrigation systems and these dams affect flow regimes and water quality.

\section{THE MEKONG RIVER CATCHMENT}

The Mekong River is one of the largest in the world with a catchment area of some 730,000 $\mathrm{km}^{2}$ and a river length of approximately $4300 \mathrm{~km}$, flowing from the Himalayas through China, Myanmar, Laos, Thailand, Cambodia and Vietnam (Figure 1). The river rises in the Himalaya on the Tibetan Plateau and then flows into Yunnan Province in China. As it travels southeast the river forms the border between Myanmar and Laos and then the border between Thailand and Laos, passing the capital of Laos at Vientiane before entering Cambodia. At Phnom Penh, the river is joined by the Tonle Sap River and then divides to generate two main branches that form the apex of the Mekong's delta. The catchment geology is highly variable, ranging from Himalayan bedrock to sedimentary soils in the lower reaches (Carling, 2009), with the river being subject to powerful erosional processes driven by the high monsoon rainfalls and flows. Sediment delivery is historically significant but declining (Darby et al., 2016). This sediment flux plays a large role in maintaining the morphology and stability of the downstream delta system. The Mekong recently has been subject to extensive dam building and this process is continuing with many new dams being planned (Kondolf et al., 2014). Many of the dams are used for generating hydropower, while storage dams are also being developed to supply communities and to sustain agriculture via irrigation schemes (Dunn, 2017). The catchment is a large supplier of food crops, including glutinous rice, maize and cassava, and much of this is sustained by the irrigation waters. Drought is by far the major hydrological hazard in this region, but large floods are also a problem, especially in the lower reaches and in the delta (Dung et al., 2015, Lee et al., 2018, Smaijgl et al., 2015). 
A key element of this present study has been to characterise and model the catchment of the river system, using a 24 sub-catchment model set up, as shown in Figure 1. Table 1 shows the sub-catchment characteristics, including sub-catchment areas, reach length and the main cities located along the river system. Land use is a key factor determining water quality and hydrology, as fertilised agricultural crops can deliver excess nutrients into rivers (Whitehead, 1990) and forests will alter hydrological mass balance (Buendia et al., 2016; Herrero et al., 2017). Table 2 shows the land use percentages for the multiple reaches analysed here and Figure 2 shows the mean phosphorus and nitrate- $\mathrm{N}$ concentrations for water quality based on monthly mean data from the Mekong River Commission. Interestingly, the nitrate- $\mathrm{N}$ data show higher levels in the upper reaches of the catchment, derived from the relatively high populations in Yunnan Province in China, whereas phosphorus levels tend to build up down the river system, with higher values at the Vietnamese border. The Tonle Sap Lake exchanges considerable volumes of water with the lower Mekong and nutrient levels are high from the lake, reflecting the intense agricultural development around the lake system (Campbell et al., 2009).

The Mekong's water and nutrients ( $\mathrm{N}$ and $\mathrm{P}$ ) are transported down the catchment from the headwater into the delta areas. These nutrients and water fluxes drive the dynamics of the delta system in terms of ecological sustainability, whilst supporting vital ecosystem services required for food production and fishing, thereby sustaining human livelihoods. However, too many nutrients can also cause problems such as eutrophication, generating algal blooms and low oxygen levels. Thus, it is important to know how future changes upstream coupled with climate change will affect future water flows and nutrient fluxes.

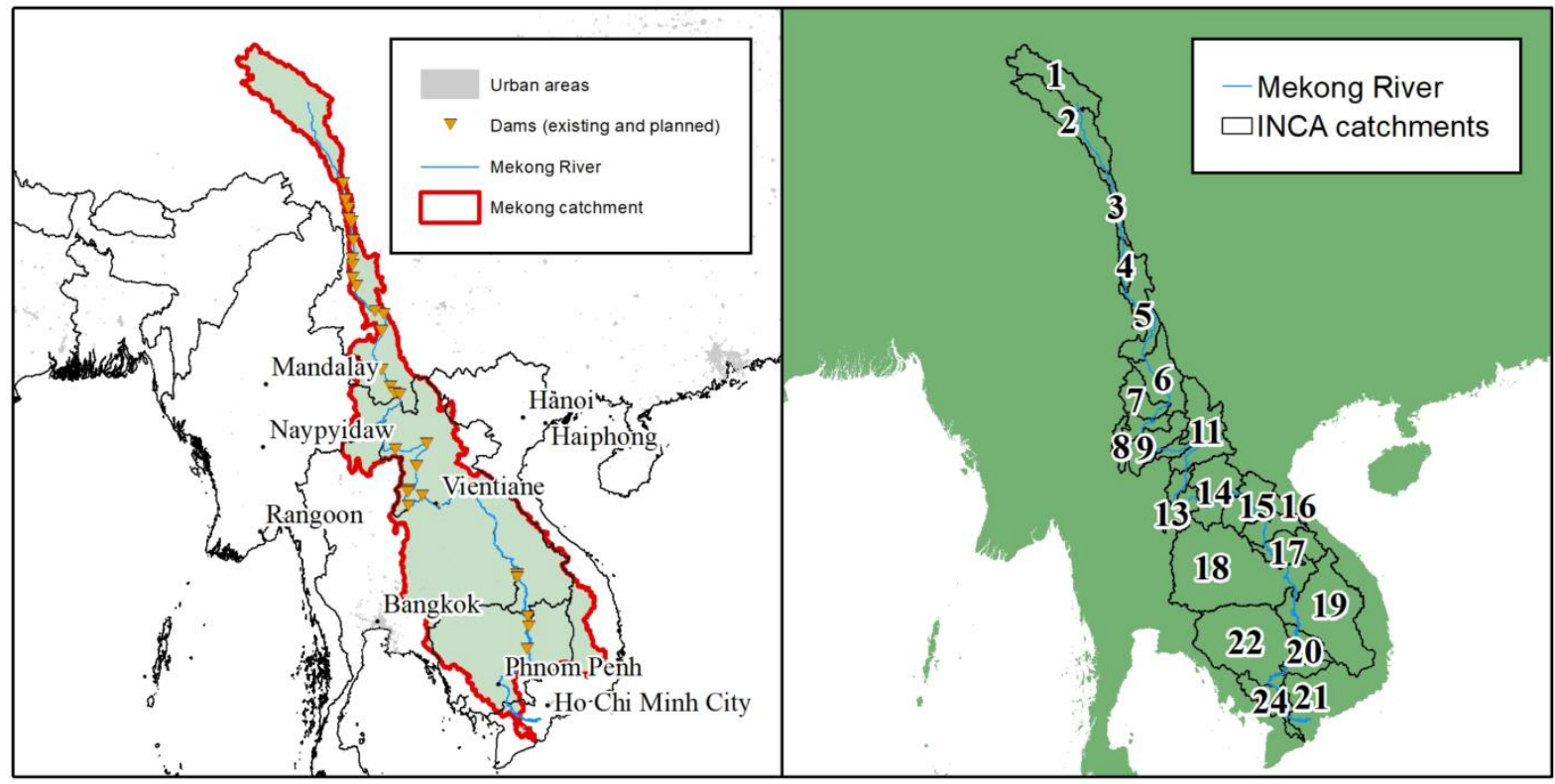

Figure 1 Location of the Mekong River system showing major cities (left) and the subcatchment and reach structure employed in this study (right). 
Table 1 Sub-Catchment lengths, areas and main locations

\begin{tabular}{|c|c|c|c|}
\hline Sub-basin & Reach Name & Length $(\mathrm{km})$ & Area $\left(\mathrm{km}^{2}\right)$ \\
\hline 1 & Source & 310.58 & 24844.50 \\
\hline 2 & Reach 2 & 363.60 & 77035.97 \\
\hline 3 & Reach 3 & 277.78 & 11262.04 \\
\hline 4 & Reach 4 & 244.00 & 11643.59 \\
\hline 5 & Reach 5 & 396.03 & 39783.31 \\
\hline 6 & Reach 6 & 234.02 & 41949.68 \\
\hline 7 & Reach 7 & 123.07 & 23883.08 \\
\hline 8 & Chiang Saen & 101.88 & 11805.85 \\
\hline 9 & Reach 9 & 140.49 & 37539.86 \\
\hline 10 & Reach 10 & 133.28 & 7640.31 \\
\hline 11 & Luang Prabang & 141.91 & 52557.53 \\
\hline 12 & Chiang Khan & 158.35 & 9570.42 \\
\hline 13 & Vientiane & 159.30 & 17484.84 \\
\hline 14 & Nong-Khai & 199.63 & 42020.11 \\
\hline 15 & Nakhon-Phanom & 141.17 & 37592.89 \\
\hline 16 & Mukdahan & 95.95 & 20773.42 \\
\hline 17 & Savannakhet & 137.87 & 29848.73 \\
\hline 18 & Pakse & 180.95 & 141707.32 \\
\hline 19 & Stoeng Treng & 131.07 & 93042.48 \\
\hline 20 & Kampong Cham & 234.47 & 26541.39 \\
\hline 21 & Kandall & 68.75 & 1049.66 \\
\hline 22 & Phnom Penn & 46.91 & 92681.80 \\
\hline 23 & Vietnam border & 80.16 & 3840.82 \\
\hline 24 & Delta & 218.82 & 17100.44 \\
\hline
\end{tabular}




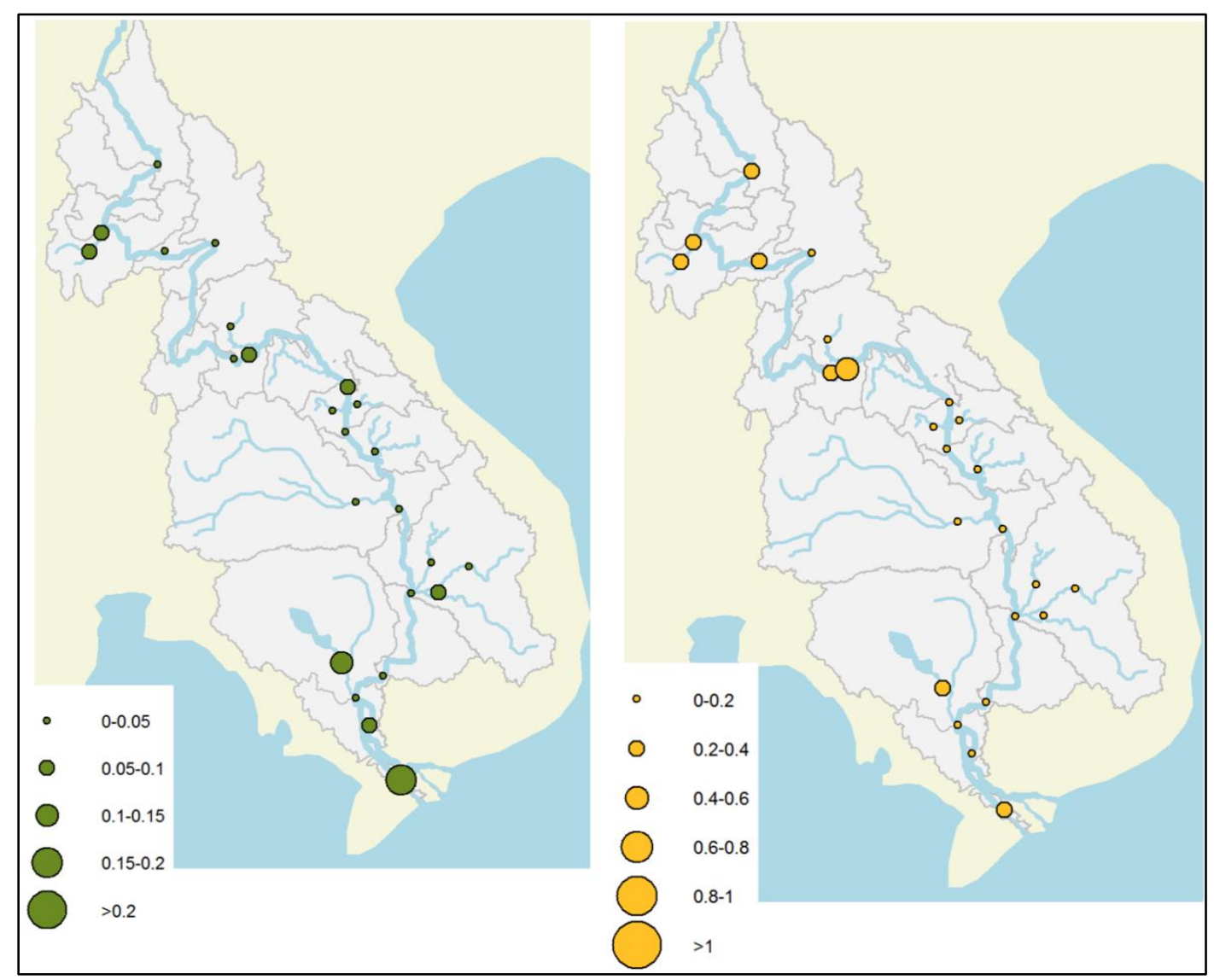

Figure 2 Mean monthly distributions of phosphorus (mg/l) (left) and nitrate- $\mathrm{N}$ (mg/l) (right) across the Mekong Catchment (data from the Mekong River Commission- monthly data from 1980 to present).

\section{INCA FLOW AND WATER QUALITY MODELLING}

The INCA (Integrated Catchment) Model is a dynamic daily simulation model that predicts flows and water quality in rivers and catchments (Whitehead et al., 1998 a, b; Wade et al., 2002 a, b). As shown in Figure 3, the primary aim of INCA is to represent the complex flow paths, interactions and connections operating in catchments of any scale from small plots or headwater catchments to very large river basins such as the Mekong. The philosophy underpinning the INCA model is to provide a process-based representation of the key factors and kinetics controlling flow and water quality dynamics in both the land and in-stream components of river catchments, whilst minimising data requirements and model structural complexity, as proposed by Young (2003). As such, the INCA model produces daily estimates of discharge, as well as stream water quality concentrations and fluxes, at discrete points along a river's main channel (the Mekong sub-catchments are shown in Figure 1). The model is semi-distributed, so that spatial variations in land use and management can be taken into account. The hydrological and nutrient fluxes from different land use classes and sub-catchment boundaries are modelled simultaneously and information fed sequentially into a multi-reach river model.

INCA was originally tested on 20 catchments in the UK, and has since been applied to over 50 catchments around the world. Of particular relevance to this study is that the model has been used to assess the impacts of climate and land use change on large river systems 
Bangladesh (Jin et al., 2015, 2018a; Whitehead et al., 2015b, 2018b), as well as highly polluted rivers in Dhaka, Bangladesh (Whitehead et al., 2018a). The major applications of INCA have been published to date in two special volumes of International Journals, namely, Hydrology and Earth System Sciences, 2002, 6, (3) and Science of the Total Environment, 2006, 365, (1-3) and there are many other publications.

Table 2 Land Use percentages in the Sub-Catchments

\begin{tabular}{|r|r|r|r|r|r|r|}
\hline $\begin{array}{l}\text { Sub- } \\
\text { basin }\end{array}$ & \multicolumn{1}{l}{$\begin{array}{l}\text { Snow } \\
\text { and ice }\end{array}$} & \multicolumn{1}{l|}{ Forest } & \multicolumn{1}{l|}{$\begin{array}{l}\text { Grasslands - } \\
\text { shrub }\end{array}$} & $\begin{array}{l}\text { Irrigate } \\
\text { d crops }\end{array}$ & \multicolumn{1}{l}{$\begin{array}{l}\text { Rain-fed } \\
\text { crops }\end{array}$} & Urban \\
\hline 1 & 2.6 & 1.4 & 29.4 & 8.1 & 58.5 & 0 \\
\hline 2 & 3.4 & 10.2 & 32.6 & 3.3 & 50.5 & 0 \\
\hline 3 & 4.2 & 51 & 24 & 0.4 & 20.4 & 0 \\
\hline 4 & 0.2 & 52.2 & 17.8 & 0.9 & 28.9 & 0 \\
\hline 5 & 0 & 36.7 & 26.7 & 2.2 & 34.3 & 0.1 \\
\hline 6 & 0 & 45.7 & 40.7 & 0.3 & 13.2 & 0.1 \\
\hline 7 & 0 & 41 & 46.7 & 0.4 & 11.9 & 0 \\
\hline 8 & 0 & 43.8 & 45.1 & 0.3 & 10.8 & 0 \\
\hline 9 & 0 & 33.7 & 41.6 & 2.8 & 21.9 & 0 \\
\hline 10 & 0 & 34.3 & 59.6 & 0.1 & 6 & 0 \\
\hline 11 & 0 & 40.4 & 56.7 & 0 & 2.9 & 0 \\
\hline 12 & 0 & 41.2 & 51.8 & 0.1 & 6.9 & 0 \\
\hline 13 & 0 & 28.9 & 28.4 & 2.3 & 40.4 & 0 \\
\hline 14 & 0 & 30.2 & 34 & 4.8 & 31 & 0 \\
\hline 15 & 0 & 41.4 & 17.7 & 6 & 34.9 & 0 \\
\hline 16 & 0 & 38.1 & 22.4 & 4 & 35.5 & 0 \\
\hline 17 & 0 & 35.4 & 26.3 & 2.7 & 35.6 & 0 \\
\hline 18 & 0 & 10.4 & 8.1 & 10.1 & 71.4 & 0 \\
\hline 19 & 0 & 47.8 & 36.8 & 0.7 & 14.7 & 0 \\
\hline 20 & 0 & 40.1 & 32.8 & 0.7 & 26.4 & 0 \\
\hline 21 & 0 & 19.4 & 6.6 & 26 & 48 & 0 \\
\hline 22 & 0 & 30.3 & 16.9 & 13.7 & 39.1 & 0 \\
\hline 23 & 0 & 15.4 & 5.3 & 34.1 & 45.2 & 0 \\
\hline 24 & 0 & 12.9 & 8.4 & 39.2 & 39.5 & 0 \\
\hline & & & & & & \\
\hline
\end{tabular}

INCA simulates flow pathways and tracks fluxes of solutes and particulates on a daily time step in both the terrestrial and aquatic portions of catchments. The model system allows the user to specify the spatial nature of a river basin or catchment, to alter reach lengths, rate coefficients, land use, velocity-flow relationships and to vary input pollutant deposition loads. In this paper we have used two versions of INCA: (i) the INCA N version that simulates flow, nitrate- $\mathrm{N}$ and ammonia- $\mathrm{N}$, and (ii) the INCA P version that simulates flow, total phosphorus (TP) and soluble reactive phosphorus (SRP). The models solve a series of interconnected differential equations for flow and water quality, as described elsewhere (Wade et al., 2002a, b; Whitehead et al., 1998 a, b). The equations are solved using the numerical integration method based on the fourth-order numerical integration Runge-Kutta routine (Whitehead et al., 1998a). The advantage of this technique is that it allows all equations to be solved 
simultaneously within a fast and stable algorithm, thereby minimizing numerical instability problems.
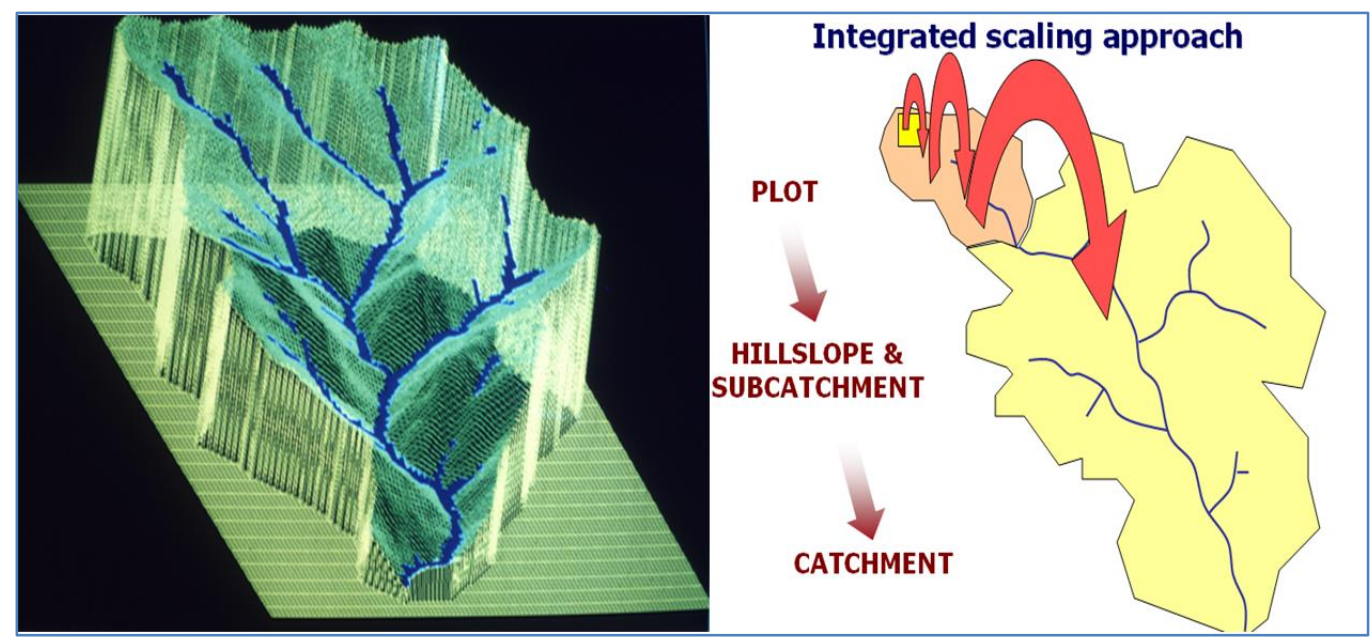

Figure 3 Catchment linkages, connectivity and scaling issues

INCA requires input data including the river network topology, reach characteristics, subcatchment areas, land use, hydrological parameters including rainfall, temperature, hydrologically effective rainfall (HER), and soil moisture deficit (SMD). HER and SMD are generated by the PERSiST model (Futter et al., 2014), which is a watershed-scale hydrological model and is a conceptual, daily time-step, semi-distributed model designed primarily for use with the INCA models.

Figure 4 shows the main flow paths and processes in INCA-P for the stream water column, the stream bed, the groundwater system and the soils system. The input fluxes that INCA-P takes into account include atmospheric deposition, inorganic fertilizer, plant residue, and livestock waste and manure application. Stream output is calculated by subtracting various output fluxes such as plant uptake and movement to firmly bound $P$ from these inputs (Wade et al., 2009). Both inputs and outputs are affected by different land use type and environmental conditions such as soil moisture and temperature. INCA-P accounts for stocks of inorganic and organic $P$ in the soil (in readily available and firmly bound forms), and TP in the groundwater and in the stream reaches (Wade et al., 2009). INCA-P accounts for reaction kinetics, nutrient recycling, exchange with the sediments and sediment diagenesis. Thus, phosphorus can build up in the soils and the sediments where they may also become bioavailable depending on soil hydrology, river velocity and temperature conditions. 


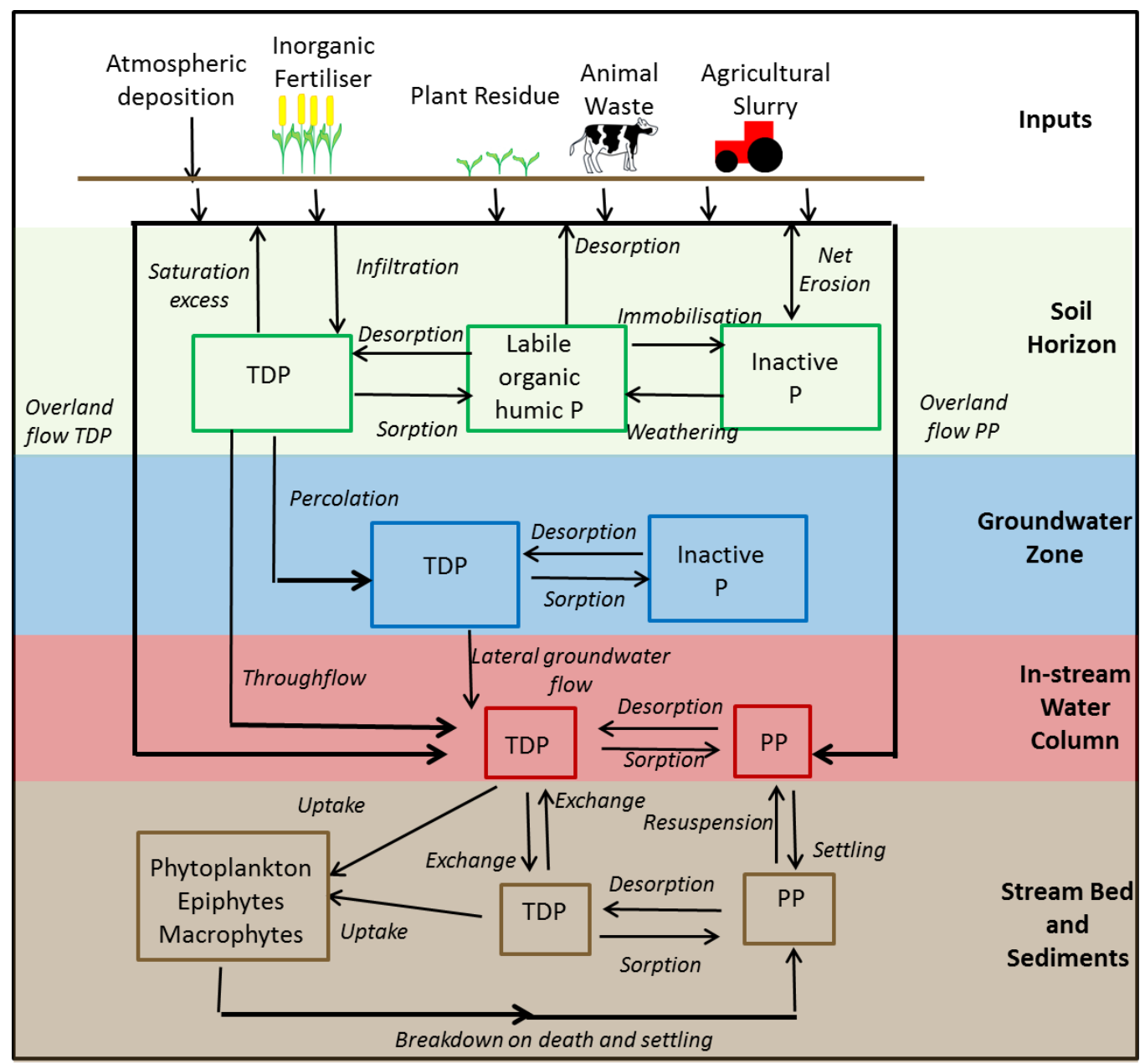

Figure 4 Description of Phosphorus processes in the INCA-P model including inputs to catchments and dynamics in soil zone, groundwater, in-stream column and streambed. TDP and PP stand for total dissolved phosphorus and particulate phosphorus, respectively (Crossman et al, 2013).

For nitrogen, the INCA-N model uses a similar approach as INCA-P with a mass balance over the soil system and the river system, as shown in Figure 5. The hydrological model provides information on the flow moving through the soil zone, the groundwater zone and the river system. Simultaneously, whilst solving the flow equations, INCA-N solves the mass balance equations for nitrate- $\mathrm{N}$ and ammonium- $\mathrm{N}$ in both the soil and groundwater zones. The key processes that require modelling in the soil zone, as shown in Figure 5, are plant uptake for nitrate and ammonia, ammonia nitrification, denitrification of nitrate, ammonia mineralisation, ammonia immobilisation and nitrogen fixation. All of these processes will vary from land use to land use and a generalised set of equations is employed, for which parameter sets are derived for different land uses. The land phase model also accounts for all the inputs affecting each land use, including dry and wet deposition of ammonia and nitrate and fertiliser addition for both (e.g. as ammonium nitrate). Also, temperature and soil moisture control certain processes so that, for example, nitrification reaction kinetics is temperature dependent and denitrification and mineralisation are both temperature and soil moisture-dependent. Along the river system, effluents can be added and processes such as denitrification of nitrate to nitrous oxide and nitrogen gas and nitrification of ammonia to nitrate are also accounted for. 


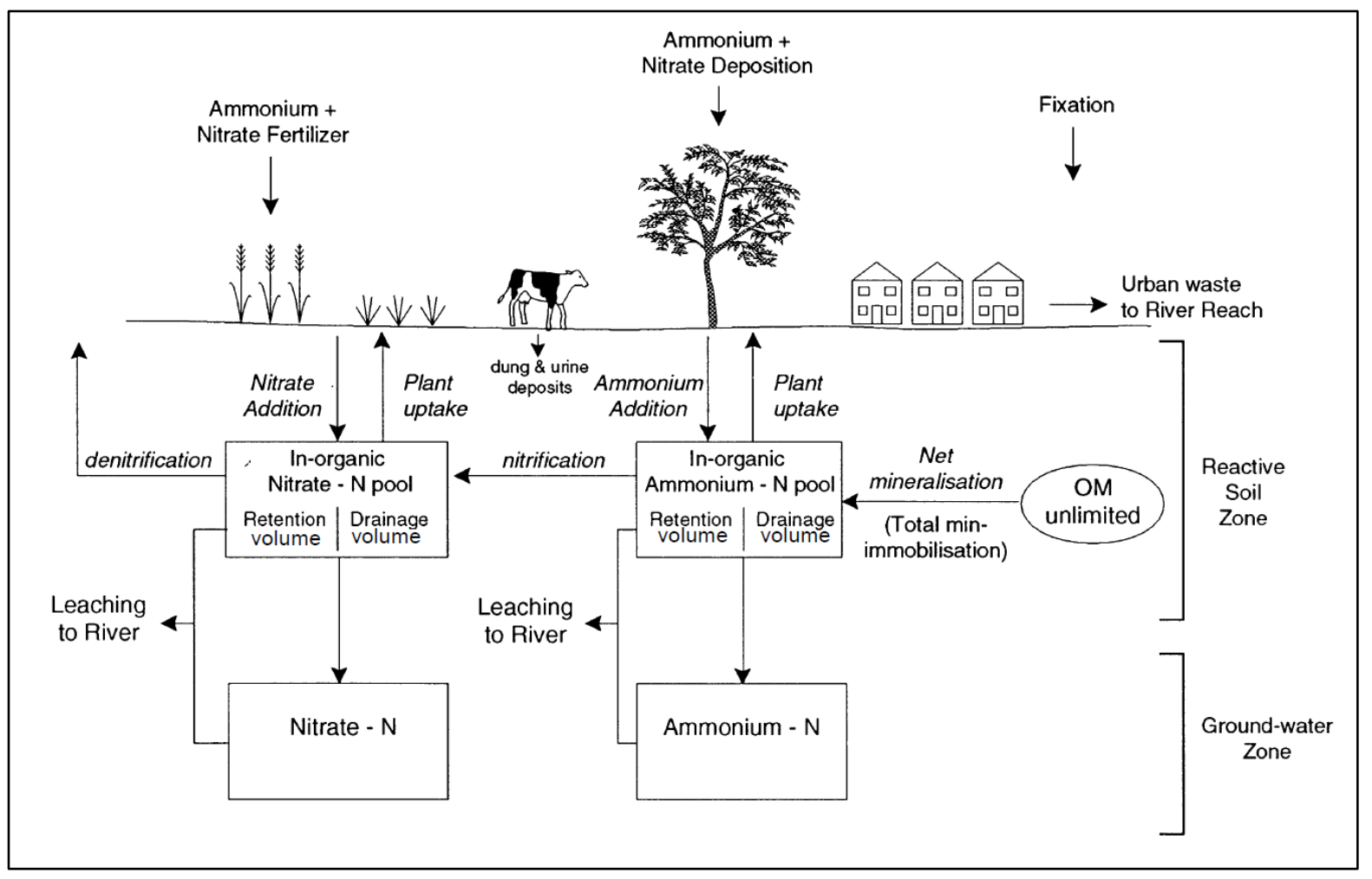

Figure 5 The nitrogen cycles operating in the INCA-N model (from Wade et al, 2002 a)

\section{APPLICATION OF THE INCA MODELS TO THE MEKONG RIVER}

The INCA-N and INCA-P models have been applied to the Mekong River system using observed flow and water quality data to calibrate and validate the models. Flow data for the period 1980-2010 at five stations, namely Jinghong (China), Mukdahan (Lao/Thailand border), Vientiane (Laos/Cambodia), Kratie (Cambodia) and Kampong Cham (Cambodia) were obtained from the Mekong River Commission (MRC). The 30 years of flow data covers a wide range of hydrological conditions, including floods and droughts, cyclones and typical river dynamics and is therefore suitable for the modelling studies.

Monthly time-series water quality data were provided by the Mekong River Commission (MRC), Technical Support Division. Physical and chemical monitoring parameters from 48 monitoring stations located on the main stream and tributaries were used. The water quality variables considered in this study were nitrate, ammonia, total phosphorus (TP) and soluble reactive phosphorus (SRP). The MRC water quality records start in the 1980s and continue to the present day, albeit with only a mean monthly data value available from the MRC.

The models were calibrated by adjusting the INCA model parameters such as flow velocity parameters, nitrogen process parameters including denitrification and nitrification, phosphorus process parameters to fit the flow and water quality records for the time period from 1980 to 1985. There has been extensive uncertainty analysis testing of the INCA models, and Wade et al. (2002 a, b) report on Monte Carlo analysis utilising the Spear and Hornberger (1980, 1981) Generalised Sensitivity Analysis Techniques to identify the key parameters controlling system behaviour. Rankinen et al. (2006) applied the GLUE (Generalized Likelihood Uncertainty Estimation) methodology, combined with quantitative experimental knowledge, to estimate the INCA-N parameters. Similarly, after performing uncertainty analysis for INCA-P using GLUE, Dean et al. (2009) concluded that the 
uncertainties in the observed values and the uncertainty associated with the model structure and parameters are similar.

The model was subsequently validated for the time period 1985 to 1990 . Nash-Sutcliffe values (NSE) (Nash and Sutcliffe, 1970) and $R^{2}$ statistics were used to assess the model performance. Table 3 shows flow model fit indices for the flow calibration, and Figure 6 shows the observed and modelled flow time series at Reaches 5, 16 and 20, representing the upper, middle and lower sections of the Mekong. Both model skill parameters show that a very good fit to the flow data is achieved. Low flows and peak flows are well simulated, which is remarkable given the size and complexity of the Mekong River system. Figure 7 shows the water quality for the simulated and observed fluxes at reaches 11 and 19 along the river system. The $R^{2}$ values obtained are both over 0.63 , indicating that the model is creating reasonable flux estimates down the river.

Table 3 Modelled River Flow Nash Sutcliffe Estimate (NSE) and $\mathrm{R}^{2}$ Indices using INCA

\begin{tabular}{|c|c|c|c|c|}
\hline & \multicolumn{2}{|c|}{$\begin{array}{c}\text { Calibration } \\
(1980-1985)\end{array}$} & \multicolumn{2}{c|}{$\begin{array}{c}\text { Validation } \\
(1985-1990)\end{array}$} \\
\hline $\begin{array}{c}\text { Catchment } \\
\text { Reach }\end{array}$ & NSE & $\mathrm{R}^{2}$ & NSE & $\mathrm{R}^{2}$ \\
\hline 5 & 0.57 & 0.69 & 0.61 & 0.69 \\
\hline 16 & 0.87 & 0.88 & 0.76 & 0.78 \\
\hline 20 & 0.85 & 0.86 & 0.80 & 0.80 \\
\hline
\end{tabular}

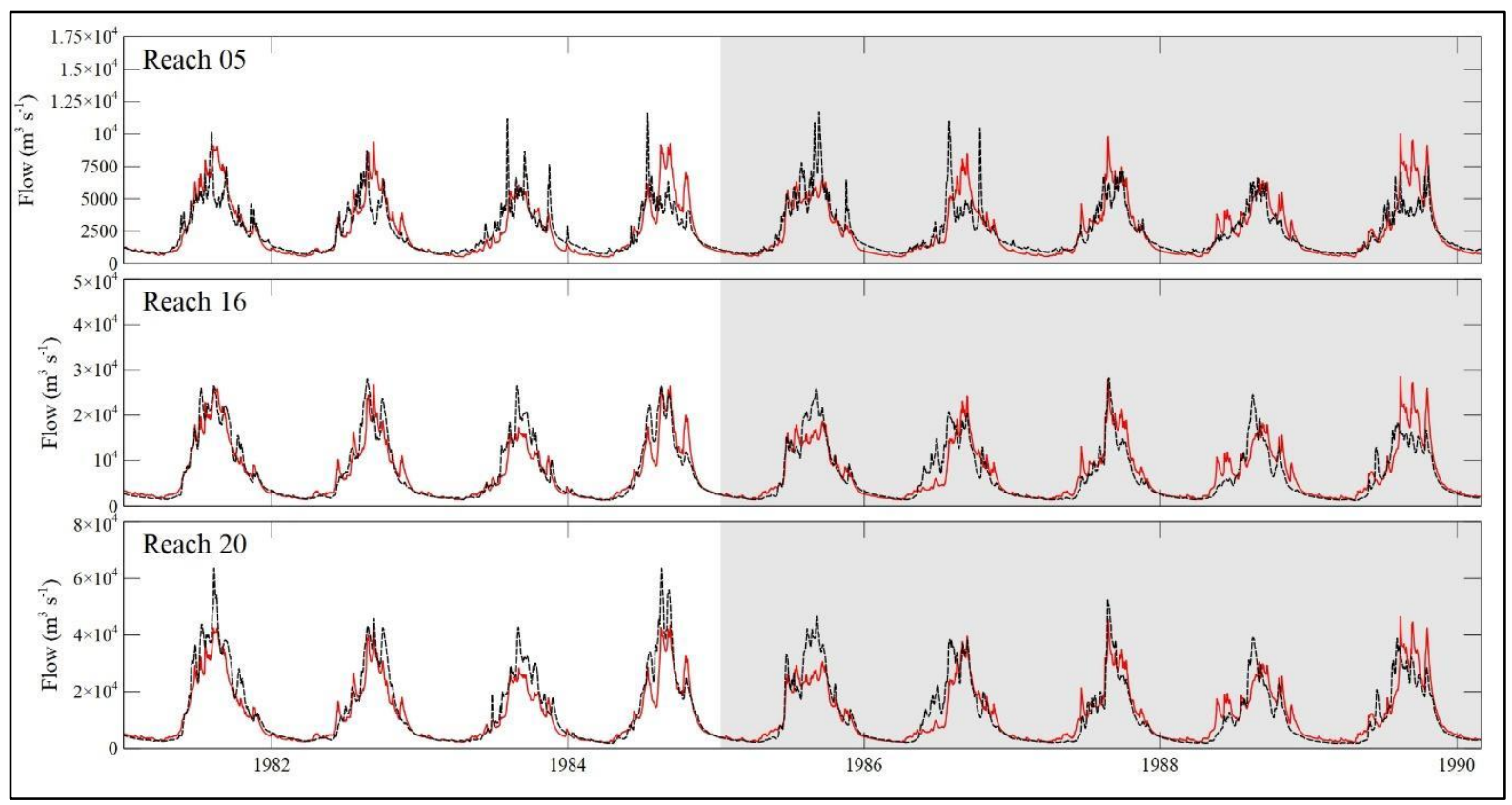

Figure 6 Flow calibration (white area) and validation (grey area) at three reaches of the flow. 


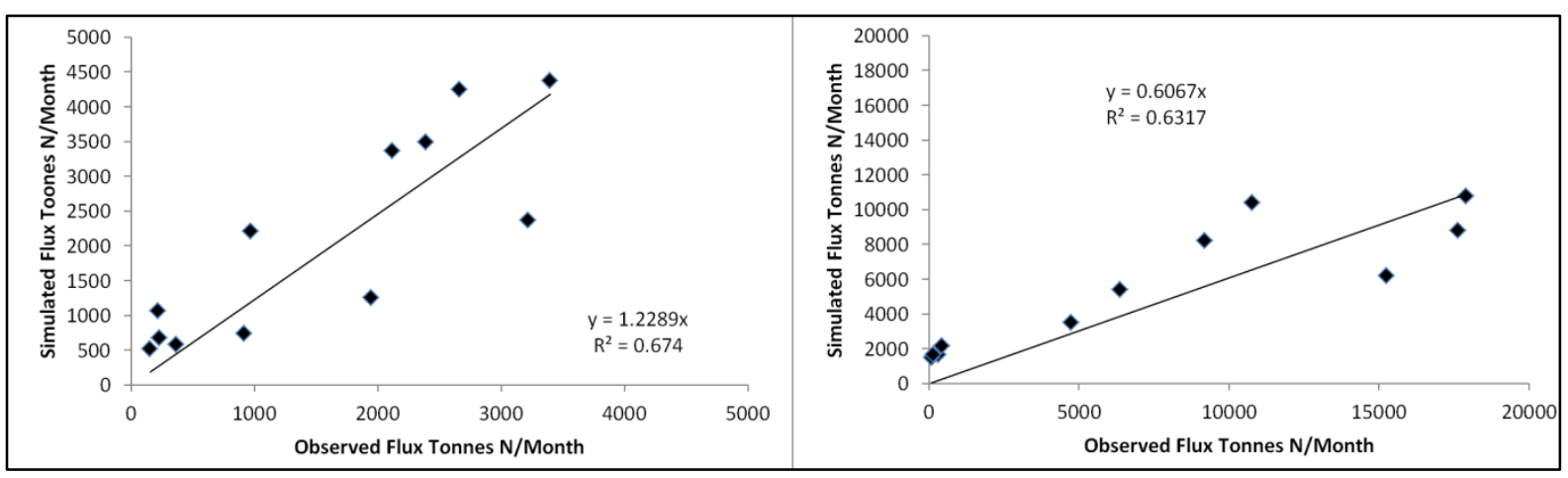

Figure 7 Monthly mean simulated and observed nitrogen fluxes at Luang-Prabang (Reach 11- left) and Stoeng-Treng (Reach 19 - right) for the period 1990 to 2010.

\section{CLIMATE AND SOCIOECONOMIC SCENARIOS FOR THE MEKONG CATCHMENT}

In order to apply INCA-N and INCA- $\mathrm{P}$ to make projections about the potential impacts of future environmental change on flow and nutrient fluxes a wealth of data and information is required, not just on climate but on future socioeconomic changes that might affect the flow and water quality. Here we describe the climate and socioeconomic scenarios that have been used for this purpose. Whilst the climate models can run to 2100 , predicting socioeconomic change up to 2100 is subject to too much uncertainty and country development plans do not extend to this time horizon. In this paper we assume a set of socioeconomic conditions pertaining to the 2050s covering damming and reservoir construction alongside changes in climate, population, land use, agriculture, and industrialisation, as detailed in the sub-sections below.

\section{Climate}

Global Circulation Models (GCMs) typically have coarse spatial resolutions with horizontal grid boxes of a few hundred kilometres in size, and cannot provide the high-resolution climate information that is often required for climate impact and adaptation studies. The use of a regionally coupled model (RCM), which dynamically downscales the GCM simulations with the RCM being driven using GCM boundary conditions, can provide higher resolution grids (typically $25 \mathrm{~km}$ or finer) and is better able to represent features such as local topography and coast lines and their effects on the regional climate. There have been relatively few climate impact studies focused upon the Mekong River Basin that have used RCM outputs (Thuc et al., 2016). Whitehead et al. (2015a) used a $25 \mathrm{~km}$ RCM resolution model over south Asia for the period 1971-2099, downscaled by the Met Office using the PRECIS RCM system, and applied the model to the Ganges, Brahmaputra and Meghna River Systems (Whitehead et al., 2015a, 2018b). The RCM was based on the atmospheric component of the HadCM3 GCM (Gordon et al., 2000) with substantial modifications to the model physics (Jones et al., 2004). For the Mekong we also employ the PRECIS RCM model using the Global Circulation Model GFDL-CM to provide the boundary conditions (Thuc et al., 2016). The combined modelling system generates daily simulations for the period 1971-2098. The climate modelling system has also been set up by the UK Met Office to produce the Representative Concentration Pathways (RCP) 4.5 and 8.5 simulations as these represent the latest Intergovernmental Panel on Climate Change (IPCC) and Paris Accord recommendations for 2 climate futures (Edenhofer et al., 2014; Janes et al., 2019; Thuc et al., 2016). RCP 8.5 is consistent with greenhouse gas emissions continuing to rise 
throughout the 21st century and represents a relatively challenging situation for climate change adaptation, but one that does not appear unrealistic given recent trends in carbon emissions. RCP 4.5 is considered the greenhouse gas release strategy required to meet the $2.0^{\circ} \mathrm{C}$ aspiration for the Paris Accord.

\section{Socio-economics}

Population change, dam development, industrial development, agricultural fertiliser use and land use change have the strong potential to affect flows and water quality in river systems and hence impact downstream coastal environments (Kebede et al., 2018; Whitehead et al., 2015b). In terms of the socio-economic scenarios for the Mekong, there are many possible futures and so we defined a narrative based on the IPCC Shared Socio-economic Pathways or SSPs (Edenhofer et al., 2014). In this study the SSP scenarios selected are based on

These 2 by 2 economic and population growth scenarios therefore produce 4 combinations and when combined with the RCP 4.5 and 8.5 climate scenarios give a total of 8 combinations that are explored herein. The following sub-sections present a brief description of the factors involved and how we have changed parameters in the model to reflect these scenarios.

\section{Future Population and Effluent Discharges}

Population forecasts for Mekong River countries (China, Laos, Thailand, Cambodia and Vietnam) vary widely depending on assumptions about fertility rate and economic well-being. UNDP population projections (UNDP, 2018) for the 2050s indicate average population increases of $18.7 \%$ under a moderate fertility rate, and a $27.3 \%$ increase under a higher growth rate, across the Mekong catchment. Population increases drive demand for food and hence agricultural and land use change. They also drive domestic effluent discharges and Table 4 shows the main areas of population and the likely point urban effluent generated under current conditions, assuming 150l/day of water usage (Chapra, 2018). As the population rises, effluents will rise proportionally and these changes can be incorporated into the models to reflect future conditions. These effluent discharges directly affect water quality as $\mathrm{N}$ and $\mathrm{P}$ concentrations in domestic effluents are quite high and of the order of $19 \mathrm{mg} / \mathrm{l}$ of ammonium- $\mathrm{N}, 15 \mathrm{mg} / \mathrm{l}$ of nitrate- $\mathrm{N}$ and $8 \mathrm{mg} / \mathrm{l}$ of phosphorus (Chapra, 2018). Construction of sewerage systems and sewage treatment plants are important in controlling effluent discharges and it is assumed here that only primary treatment is provided and not secondary or tertiary treatment to remove nutrients. 
Table 4 Current Urban Population Numbers along the Mekong and Effluent Discharges

\begin{tabular}{|c|c|c|c|}
\hline Reach & Location & Population & Effluent $\mathrm{m}^{3} / \mathrm{s}$ \\
\hline 3 & Yunnan & 2000000 & 3.11 \\
\hline 9 & Chiang Saen & 53500 & 0.09 \\
\hline 11 & $\begin{array}{c}\text { Luang } \\
\text { Prabang }\end{array}$ & 56000 & 0.1 \\
\hline 12 & Chiang Khan & 59,000 & 0.1 \\
\hline 14 & Vientiane & 196000 & 0.34 \\
\hline 14 & Nong Khai & 48000 & 0.08 \\
\hline & Nakhon & & 0.05 \\
\hline 15 & Phanom & 27000 & 0.31 \\
\hline 16 & Mukdahan & 180600 & 0.12 \\
\hline 17 & Savannakhet & 66553 & 0.15 \\
\hline 18 & Pakse & 88332 & 0.05 \\
\hline 20 & Stung Treng & 29665 & 0.03 \\
\hline 20 & Kratié & 19975 & 2.6 \\
\hline 22 & Phnom Penh & 1500000 & \\
\hline \multicolumn{3}{|c}{} \\
\end{tabular}

Future Water demand for irrigation and public supply

The demand for public water supply will increase with population growth and changes in irrigation water demand reflect changes in agriculture and land use. Increased dam developments will also affect water supply and water velocity as both run of river hydroelectric schemes will be developed, as will storage dams for irrigation purposes and public water supply. However, agricultural changes in the Mekong countries are difficult to predict as any changes will depend on factors such as world food prices, which are driven by increasing global population, potential food scarcity, and how farmers react to changing crop prices. Other key influential factors include technological developments, such as the introduction of new crop varieties adapted to changing local environmental conditions. A detailed assessment of historical and future dam development by Dunn (2017) provides an up to date analysis of dam capacity. Table 5 shows the historic and future irrigation dam volumes and flow equivalents down the Mekong for each reach along the river system. These will be the primary dams that affect river flows as they extract water from the rivers and supply the water to irrigation systems. It is generally the case that dams are rarely completely drawn down for reasons of dam safety, and so we have assumed that dams are drawn down on average by $30 \%$ (Manley, 2018, personal communication). The other type of dams on the Mekong are for hydropower and the 'run of river' dams do not remove water from the river system but just use the water temporarily to generate hydroelectricity. 


\begin{tabular}{|c|c|c|c|c|}
\hline & \multicolumn{2}{|c|}{ Historical Dams } & \multicolumn{2}{|c|}{$\begin{array}{c}\text { Future Additional } \\
\text { Dams }\end{array}$} \\
\hline $\begin{array}{l}\text { INCA } \\
\text { Reach }\end{array}$ & $\begin{array}{l}\text { Dam } \\
\text { Volume } \\
(\mathrm{MCM}- \\
\left.10^{6} \mathrm{~m}^{3}\right)\end{array}$ & $\begin{array}{c}\text { Daily Flow } \\
\text { Equivalent } \\
\mathrm{m}^{3} / \mathrm{sec}\end{array}$ & $\begin{array}{c}\text { Dam } \\
\text { Volume } \\
\text { (MCM- } \\
\left.10^{6} \mathrm{~m}^{3}\right)\end{array}$ & $\begin{array}{c}\text { Daily Flow } \\
\text { Equivalent } \\
\mathrm{m}^{3} / \mathrm{sec}\end{array}$ \\
\hline 3 & & & 75 & 2 \\
\hline 4 & 316 & 10 & & \\
\hline 5 & 16525 & 524 & & \\
\hline 6 & 25263 & 801 & & \\
\hline 7 & & & 1479 & 46 \\
\hline 10 & 3611 & 114 & 2909 & 92 \\
\hline 11 & 2082 & 66 & 8582 & 272 \\
\hline 12 & & & 4210 & 133 \\
\hline 13 & & & 1378 & 43 \\
\hline 14 & 9230 & 292 & 4057 & 128 \\
\hline 15 & 6500 & 206 & 2772 & 87 \\
\hline 16 & 165 & 5 & & \\
\hline 18 & 7163 & 227 & 4186 & 132 \\
\hline 19 & 15694 & 497 & 5149 & 163 \\
\hline 20 & & & 3794 & 120 \\
\hline
\end{tabular}

403

404

405

406

407

408

409

410

411

412

413

414

415

416

417

418

419

420

421

422

423

424

425

426

Future Land use change

The Mekong River Commission and the UN Food and Agriculture Organisation (FAO) (World Agriculture Report 2013) have reviewed projected changes in agriculture in the Mekong Catchment and associated countries. Agriculture is vital to raising standards of living, to improving livelihoods and to poverty reduction in the basin. There are over 12,500 irrigation schemes, with farmers producing enough rice to feed 300 million people per year (Mekong River Commission, 2010). The predicted changes in agriculture include a significant expansion of irrigated and rain-fed agriculture, with consequent reductions in forest cover, resulting in an increased area of double/triple crops to meet enhanced food demands. There is also predicted to be increased use of fertilizers to boost crop yields, resulting in increases in agricultural production estimated to be between $30 \%$ and $45 \%$, according to the FAO World Agriculture Report 2013. Interestingly, these changes match the projected increases in dam capacity for irrigation (Table 5). In order to account for such change in the INCA modelling we use the $45 \%$ and $30 \%$ increases in agriculture as a high growth rate and as a moderate growth rate, respectively, with consequential reductions in forest cover.

\section{Future Atmospheric Nitrogen Deposition}

Atmospheric nitrogen pollution has become an increasing problem around the world, as industrial development, power generation and ammonia release from intensive agriculture has expanded. For example, across Europe, a set of Nitrogen Protocols have been established by the UN/ECE Commission of Transboundary Pollution and these protocols have been agreed and implemented by all EU countries. Deposition can be high, with $25 \mathrm{~kg}$ $\mathrm{N}$ per hectare per year being deposited in certain parts of Europe, such as the UK. Across Asia, nitrogen deposition is also of concern and there have been empirical studies as well as critical load assessments (Duan et al., 2016; Hettelingh et al., 1995). 
The effect of high atmospheric $\mathrm{N}$ is to alter the terrestrial ecology of plants and natural vegetation, and provide a baseline source of $\mathrm{N}$ to groundwaters and streams, which can then affect aquatic ecology. Research in the Himalayas (Collins et al., 1999), in which INCA $\mathrm{N}$ was applied to a range of basins, suggests generally low concentrations of atmospheric $\mathrm{N}$. Across India, however, levels are likely to be much higher, with greater urban and industrial sources of atmospheric N (Whitehead et al., 2018b, 2015b). In the future, in the Mekong catchment, increased industrial development and more intensive farming methods will cause atmospheric $\mathrm{N}$ concentrations to increase. INCA $\mathrm{N}$ can incorporate these effects as deposition loads to the sub-basins, and thus $\mathrm{N}$ levels are altered in the projections showed in this paper to reflect the different socio-economic scenarios into the future. It has been assumed that current $\mathrm{N}$ deposition rates are in line with those reported by Adon et al. (2015) of $5 \mathrm{~kg} / \mathrm{ha} /$ year of wet deposition and $3.8 \mathrm{~kg} / \mathrm{ha} / \mathrm{year}$ of dry deposition. Under the moderate growth scenario, we assume that these deposition rates will increase to $7 \mathrm{~kg} / \mathrm{ha} /$ year and 5 $\mathrm{kg} / \mathrm{ha} /$ year for wet and dry deposition respectively, by the 2050s, generating a total $\mathrm{N}$ deposition of $12 \mathrm{~kg} / \mathrm{ha} / \mathrm{year}$. Under the high growth rate scenario, we assume that total $\mathrm{N}$ deposition will reach $15 \mathrm{~kg} / \mathrm{ha} / \mathrm{year}$ by the $2050 \mathrm{~s}$.

\section{RESULTS OF SCENARIO ASSESSMENT}

In this section we discuss the results of the model projections under the various scenarios described above.

1. Two climate scenarios (RCP 4.5 and 8.5 , representing the Paris Accord $1.5^{\circ} \mathrm{C}$ rise and a $3-4{ }^{\circ} \mathrm{C}$ rise, respectively).

2. Two socioeconomic scenarios representing a high growth future and a moderate growth future.

3. Two population scenarios with a high population growth and a lower sustainable population growth.

\section{Climate Change Impacts}

Figure 8 shows the model decadal projections for altered river flows through to the end of the century under each of the two climate change scenarios. A rising trend in mean, low and high flows is observed in Figure 8. These results are summarised in Table 6, where the projected percentage changes in mean, Q5 and Q95 river flows from the 1998-2017 conditions are shown. Q5 and Q95 represent the extremes of flow with Q5 representing the flow rate that is equalled or exceeded for $95 \%$ of the time and Q95 the flow rate that is equalled or exceeded for $5 \%$ of the time. Thus Q5 characterises the high flow or flood conditions with Q95 representing the low flow condition. The RCP 4.5 results suggest that there will not be large changes in mean flow conditions by the 2050s but that mean flows will increase substantially by $24 \%$ towards the end of the century. High flow conditions (Q5) will increase by $27 \%$ by the end of the century under both scenarios and these changes in high flows suggest increased flooding events along the Mekong. Interestingly the low flows (Q95) decline slightly by the 2050s, suggesting increased low flow periods or enhanced droughts by the mid-century. 
Table 6 Projected percentage changes in flow for the 2050s and 2090s from current (19982017) conditions under the RCP 4.5 and RCP 8.5 scenarios

471

472

473

474

475

476

477

478

479

480

481

482

483

484

485

486

487

488

489

490

491

492

493

\begin{tabular}{|c|c|c|c|c|c|c|}
\hline & \multicolumn{3}{|c|}{ Climate Scenario GFDL 4.5 } & \multicolumn{3}{c|}{ Climate Scenario GFDL 8.5 } \\
\hline & Mean & Q5 & Q95 & Mean & Q5 & Q95 \\
\hline $2040-2060$ & -0.04 & 4.22 & -0.74 & 19.00 & 12.72 & 10.71 \\
\hline $2080-2100$ & 24.11 & 27.19 & 17.88 & 27.39 & 26.63 & 13.73 \\
\hline
\end{tabular}

The results are also interesting when considered from a monthly or seasonal perspective. Figure 9 shows the monthly flows and water quality for current conditions for the 2050s and the 2090s under the RCP 4.5 and the RCP 8.5 climate scenarios. The peak flow clearly increases, but there is also a shift in the distribution of the monthly flows, with the monsoon flows arriving almost one month earlier than current conditions by the 2050s. This shift in timing is also seen in the RCP 8.5 scenario. This is quite a dramatic result and could mean flooding issues will arise earlier in the year and also suggests a longer monsoon period.

The water quality results as shown in Figure 9 tend to reflect the rising flow conditions. The nitrate- $\mathrm{N}$ results show reduced concentrations in the low flow conditions, reflecting the denitrification processes operating in the river, but increases in nitrate- $\mathrm{N}$ in the monsoon flows. This suggests a flushing of $\mathrm{N}$ out of the soils and the catchments driven by the wetter conditions and higher soil water flows. This behaviour is seen elsewhere after dry or drought conditions (Whitehead 1990). Phosphorus shows a very different pattern, with high concentrations in the low flow periods and substantial reductions in the monsoon flows. Both these patterns are consistent with point source pollution for towns and cities along the river with limited dilution of effluents in low flows, thereby generating higher phosphorus concentrations. The monsoon flows then dilute the effluents and thus create lower concentrations.

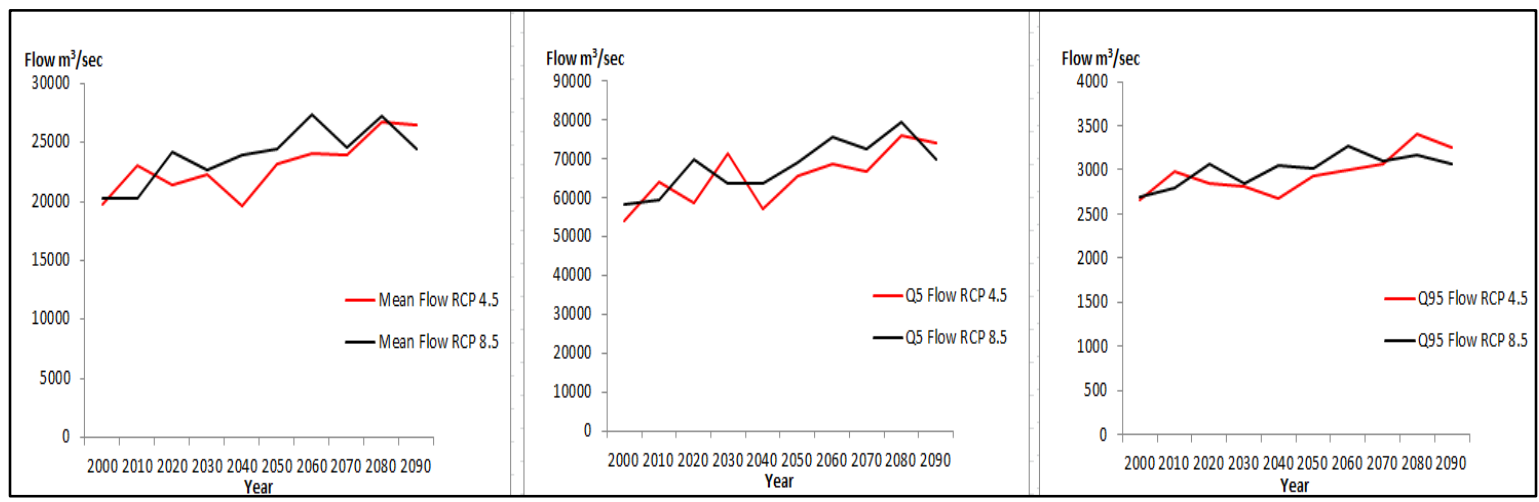

Figure 8 Future decadal changes in flow (Mean, Q5 and Q95) under RCP 4.5 and 8.5 carbon emission scenarios. 


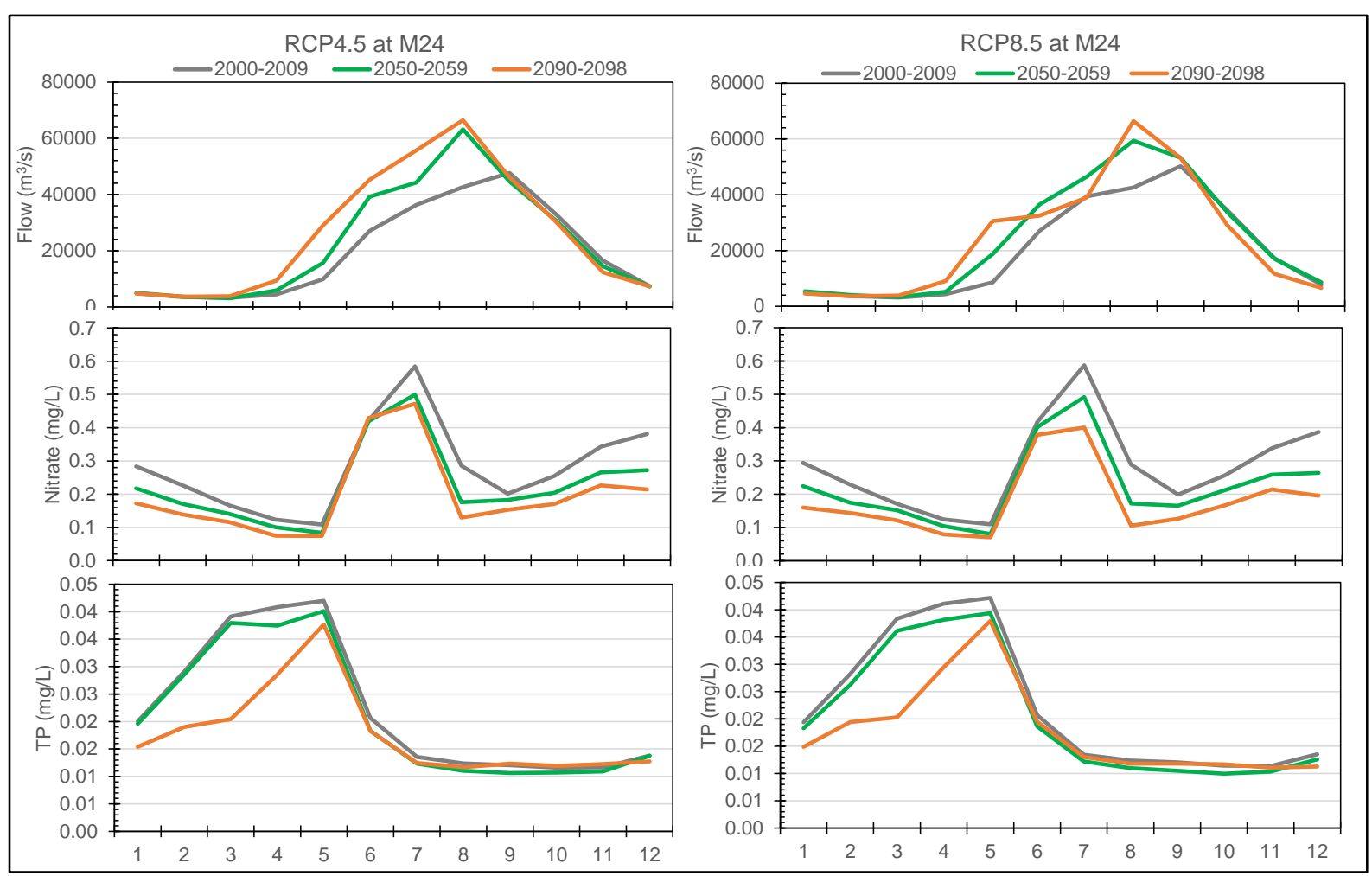

Figure 9 Mekong monthly flow and nitrate-N and total phosphorus (TP) concentrations at the Mekong delta apex for the baseline period, and the 2050s and 2090s for the RCP 4.5 and

RCP 8.5 carbon scenarios.

\section{Combined Climate and Socioeconomic Change}

500 The combined results of the climate change and socio-economic changes are presented in Tables 7 and 8 and show the percentage changes for river flows and water quality from the baseline conditions as well as the flux transport of nutrients. The results suggest that socioeconomic change as modelled here do not result in a major response of the flows, partly because of the sheer volume of monsoon flows and the overwhelming impact of increased precipitation, although dam development may affect low flows. The water quality trajectories are also quite consistent and show that the socioeconomics do not alter water quality significantly but that climate change and the increased flows dominate, generating reduced nutrient concentrations due to the dilution effects of increased monsoon flows. The total phosphorus increases in the high growth and high population simulations, but falls in the low population scenarios reflecting the reduced effluent discharges. These concentration changes are reflected in the flux calculations. There is a large load of nitrogen and phosphorus delivered to the Mekong delta, of the order of 180,000 tonnes of $N$ and 12,000 tonnes of $P$ per year. These fluxes help to provide key nutrients for the delta's agricultural system, but will also contribute to elevated eutrophication risk in the delta, coastal and ocean system. Eutrophication could be a very important problem in the future, as excessive nutrient loads will increase algal blooms. These blooms eventually die and decay generating a high organic load on the water system which will reduce dissolved oxygen levels. Low oxygen levels can damage fisheries and livelihoods in coastal and delta systems.

519 Future fluxes look likely to change slightly, with decreases of $8.3 \%$ and $0.7 \%$ for $\mathrm{N}$ and $\mathrm{P}$ 
myriad of factors controlling nutrient behaviour, including changing flows (and hence 523 residence times), dam development, temperatures, agriculture and land use and population.

524 Table 7 Flow and Water Quality Percentage Changes from Baseline Conditions under 525 Combined Climate and Socio-economic Scenarios for the 2050s (pop = population number)

\begin{tabular}{|l|r|r|r|r|r|r|}
\hline & \multicolumn{3}{|c|}{ Flow \% Change } & Water Quality \% Change \\
\hline Scenario & Mean & Q5 & Q95 & Nitrate & TP \\
\hline RCP 4.5 High Growth High Pop. & -0.1 & 5.9 & 1.6 & -7.2 & 1.59 \\
\hline RCP 4.5 High Growth Low Pop. & -0.1 & 5.9 & 1.5 & -7.62 & -2.69 \\
\hline RCP 4.5 Medium Growth High Pop. & -0.1 & 5.9 & 1.6 & -8.98 & 1.53 \\
\hline RCP 4.5 Medium Growth Low Pop. & -0.1 & 5.9 & 1.5 & -9.4 & -2.96 \\
\hline RCP 8.5 High Growth High Pop. & 13.4 & 14.7 & 10.8 & -7.35 & -11.87 \\
\hline RCP 8.5 High Growth Low Pop. & 13.4 & 14.7 & 10.8 & -7.73 & -15.29 \\
\hline RCP 8.5 Medium Growth High Pop. & 13.4 & 14.7 & 10.8 & -9.16 & -11.84 \\
\hline RCP 8.5 Medium Growth Low Pop. & 13.4 & 14.7 & 10.8 & -9.54 & -15.25 \\
\hline
\end{tabular}

Table 8 Nitrogen and Phosphorus Fluxes at Baseline Conditions and under Combined Climate and Socio-economic Scenarios for the 2050s (pop = population number, Tonnes $/$ year $=10^{3} \mathrm{~kg} /$ year)

\begin{tabular}{|l|r|r|r|r|}
\hline & \multicolumn{2}{|c|}{ Flux Tonnes/year } & \multicolumn{2}{c|}{ Flux \% Change } \\
\hline & Nitrate & Phosphorus & Nitrate & Phosphorus \\
\hline Baseline 1998-2017 & 180651 & 11824 & & \\
\hline RCP 4.5 High Growth High Pop. & 167559 & 12006 & -7.2 & 1.5 \\
\hline RCP 4.5 High Growth Low Pop. & 166795 & 11500 & -7.7 & -2.7 \\
\hline RCP 4.5 Medium Growth High Pop. & 164346 & 11999 & -9.0 & 1.5 \\
\hline RCP 4.5 Medium Growth Low Pop. & 163581 & 11468 & -9.4 & -3.0 \\
\hline RCP 8.5 High Growth High Pop. & 189852 & 11820 & 5.1 & 0.0 \\
\hline RCP 8.5 High Growth Low Pop. & 189066 & 11361 & 4.7 & -3.9 \\
\hline RCP 8.5 Medium Growth High Pop. & 186143 & 11824 & 3.0 & 0.0 \\
\hline RCP 8.5 Medium Growth Low Pop. & 185358 & 11366 & 2.6 & -3.9 \\
\hline
\end{tabular}

\section{CONCLUSIONS}

This study is one of the first water quality impact studies for the whole Mekong catchment with the combined assessment of climate change and socioeconomic change. Also, for the first time a process based dynamic model of flow and water quality has been applied to the entire Mekong catchment from the Himalaya to the delta in Vietnam. The model projections provide valuable insights into how water quality and flow might change into the future, knowledge that is invaluable for planners and local stakeholders to assess impacts of environmental change and can be used to support planning and strategic decision making in the Mekong River System.

There are many uncertainties associated with simulating water quality in river basins, with extensive information being required about the catchment physical and chemical characteristics. Fortunately, in the case of the Mekong, the Mekong River Commission has some excellent data sets for flow and water quality and there are now many digital terrain and land use maps online that can be accessed. One area that seems always difficult to estimate is the type and amount of fertilizers that farmers are using (and will use in the future) and only generic information is often available. In the Mekong it is anticipated that agriculture will become more intensive over time, so that nutrient levels may increase. 
From this study, it appears that climate change will substantially affect river flow and water quality into the future, with larger mean flows and a strong likelihood of enhanced flooding and also extended drought periods. The low flows will also be exacerbated by the myriad of dams being built in the upstream catchment and over time these will reduce low flows in the dry periods. Moreover, a shift in the seasonal patterns is projected, with flow with the monsoon arriving a month earlier than at present, which could have an impact on agriculture and livelihoods, requiring new policy and planning strategies. These changing flows will alter water quality conditions by dilution during the monsoon floods and thus will alter the fluxes of nutrients entering the delta system in Vietnam. The nutrients will have positive and negative effects, perhaps enhancing agriculture as higher nutrients will increase crop production, but with a potential negative effect of exacerbating eutrophication in the estuary and in coastal waters. This could generate excessive algal blooms and also create low oxygen concentrations, thereby damaging ecological diversity.

\section{ACKNOWLEDGMENTS}

The authors are grateful for support from the project BRAgS, Building Resilient Agricultural

Systems: Sustainable Livelihoods in Mega Deltas under Environmental Change. The project has been funded by the Biotechnology and Biological Sciences Research Council under a Global Challenges Research Foundation Award for Global Agriculture and Food Systems Research (BB/P022693/1)

\section{REFERENCES}

Adon, M., Galy-Lacaux, C., Serça, D., Guedant, P., Vonghamsao, A., Rode, W., Meyerfeld, Y., Guerin, F., (2015). Atmospheric nitrogen deposition in a subtropical hydroelectric reservoir (Nam Theun II case study, Lao PDR) First assessment of nitrogen deposition budget following the impoundment of a subtropical hydroelectric reservoir (Nam Theun II, Lao PDR).

Allen, M.R., (2003). Liability for climate change. Nature 421, 891-892. doi:10.1038/421891a

Buendia, C., Bussi, G., Tuset, J., Vericat, D., Sabater, S., Palau, A., Batalla, R.J., (2016). Effects of afforestation on runoff and sediment load in an upland Mediterranean catchment. Sci. Total Environ. 540, 144-157. doi:10.1016/j.scitotenv.2015.07.005

Bussi, G., Dadson, S.J., Prudhomme, C., and Whitehead, P.G., 2016a, Modelling the future impacts of climate and land-use change on suspended sediment transport in the River Thames (UK): Journal of Hydrology, v. 542, p. 357-372.

Bussi, G., Whitehead, P.G., Bowes, M.J., Read, D.S., Prudhomme, C., Dadson, S.J., 2016b. Impacts of climate change, land-use change and phosphorus reduction on phytoplankton in the River Thames (UK). Sci. Total Environ. 572, 1507-1519. doi:10.1016/j.scitotenv.2016.02.109

Campbell, I C (ed.) 2009 The Mekong: Biophysical Environment of an International River. Oxford, GB. Academic Press, pp. 432

Carling, P. A. (2009), The geology of the lower Mekong river. In, Campbell, Ian Charles (ed.) The Mekong: Biophysical Environment of an International River. Oxford, GB. Academic Press, pp. 13-28.

Chapra, S.C., 2018, Water Quality, Handbook of Environmental Engineering, 333-349.

Collins, R., Whitehead, P.G. And Butterfield, D. (1999) Nitrogen Leaching from Catchments in the Middle Hills of Nepal; an application of the INCA model, Science of the Total Environment, 228, 259-274. 
Crossman, J., Futter, M.N., Oni, S.K., Whitehead, P.G., Jin, L., Butterfield, D., Baulch, H., Dillon, P.J. 2013. Impacts of climate change on hydrology and water quality: future proofing management strategies in the Lake Simcoe watershed, Canada. J Great Lakes Res. 39:19-32.

Darby, S.E., Hackney, C.R., Leyland, J., Kummu, M., Lauri, H., Parsons, D.R., Best, J.L., Nicholas, A.P., Aalto, R., 2016. Fluvial sediment supply to a mega-delta reduced by shifting tropical-cyclone activity, Nature 539(7628): 276-279.

Dean, S., Freer, J., Beven, K., Wade, A.J., and Butterfield, D., 2009, Uncertainty assessment of a process-based integrated catchment model of phosphorus: Stochastic Environmental Research and Risk Assessment, v. 23, p. 991-1010.

Duan, L., Q. Yu, Q. Zhang, Z. Wang, Y. Pan, T. Larssen, J. Tang, and J. Mulder. (2016). Acid deposition in Asia: emissions, deposition, and ecosystem effects. Atmospheric Environment 146, 55-69.

Dung, N. V., B. Merz, A. Bardossy, H. ApelHandling uncertainty in bivariate quantile estimation-An application to flood hazard analysis in the Mekong Delta. J. Hydrol., 527 (2015), pp. 704-717

Dunn, F.E., (2017). Multidecadal fluvial sediment fluxes to major deltas under environmental change scenarios: projections and their implications. University of Southampton.

Edenhofer, O., Pichs-Madruga, R., Sokona, Y., Farahani, E., Kadner, S., Seyboth, K., Adler, A., Baum, I., Brunner, S., Eickemeier, P., Kriemann, B., (2014). Summary for policymakers climate change 2014, mitigation of climate change. IPCC 2014, Climate Change 2014: Contribution of Working Group III to the Fifth Assessment Report of the Intergovernmental Panel on Climate Change.

FAO, 2013, The State of Food and Agriculture, World Agriculture Report, Food and Agriculture Organisation, Rome pp 156.

Fan, H., He, D., \& Wang, H. (2015). Environmental consequences of damming the mainstream lancang-mekong river: A review. Earth-Science Reviews, 146(2), 77-91.

Futter, M.N., Erlandsson, M.A., Butterfield, D., Whitehead, P.G., Oni, S.K., Wade, A.J., 2014. PERSiST: a flexible rainfall-runoff modelling toolkit for use with the INCA family of models. Hydrol. Earth Syst. Sci. 18, 855-873. doi:10.5194/hess-18-855-2014

Gordon, C., Cooper, C., Senior, C.A., Banks, H., Gregory, J.M., Johns, T.C., Mitchell, J.F.B., Wood, R.A., 2000. The simulation of SST, sea ice extents and ocean heat transports in a version of the Hadley Centre coupled model without flux adjustments. Clim. Dyn. 16, 147-168. doi:10.1007/s003820050010

Herrero, A., Buendía, C., Bussi, G., Sabater, S., Vericat, D., Palau, A., Batalla, R.J., 2017. Modeling the sedimentary response of a large Pyrenean basin to global change. J. Soils Sediments 17. doi:10.1007/s11368-017-1684-6

Hettelingh, J.P., H. Sverdrup, and D. Zhao. 1995. Deriving critical loads for Asia. Water, Air, and Soil Pollution 85(4):2565-2570.

Hoang, L P., van Vliet, M T.H., Kummu, M., Lauri, H., Koponen, J., Supit, I., Leemans, R., Kabat, P., Fulco, L. (2019) The Mekong's future flows under multiple drivers: How climate change, hydropower developments and irrigation expansions drive hydrological changes, Science of The Total Environment, 649, 601-609, ISSN 0048-9697, https://doi.org/10.1016/j.scitotenv.2018.08.160.

Hornberger, G. M. and Spear, R. C., 1980 Eutrophication in peel inlet: The problem-defining behaviour and a mathematical model for the phosphorus scenario, In Water Research, 
Volume 14, Issue 1, 1980, 29-42, ISSN 0043-1354, https://doi.org/10.1016/00431354(80)90039-1.

IPCC, (2014), Summary for Policymakers, In: Climate Change 2014, Mitigation of Climate Change. Contribution of Working Group III to the Fifth Assessment Report of the Intergovernmental Panel on Climate Change [Edenhofer, O., R. Pichs-Madruga, Y. Sokona, E. Farahani, S. Kadner, K. Seyboth, A. Adler, I. Baum, S. Brunner, P. Eickemeier, B. Kriemann, J. Savolainen, S. Schlömer, C. von Stechow, T. Zwickel and J.C. Minx (eds.)]. Cambridge University Press, Cambridge, United Kingdom and New York, NY, USA.

Jackson-Blake, L., Wade, A.J., Futter, M., Butterfield, D., Couture, R.M., Cox, R.M., Crossman, J., Ekholm, P., Halliday, S., Jin, L., Lawrence, D.S.L., Lepisto, A., Lin, Y., Rankinen, K., Whitehead, P.G., (2016). The INtegrated CAtchment model of Phosphorus dynamics (INCA-P): description and demonstration of new model structure and equations. Environ. Model. Softw. doi:10.1016/j.envsoft.2016.05.022

Jackson-Blake, L.A., Starrfelt, J., (2015). Do higher data frequency and Bayesian autocalibration lead to better model calibration? Insights from an application of INCA-P, a process-based river phosphorus model. J. Hydrol. 527, 641-655. doi:10.1016/j.jhydrol.2015.05.001

Janes, T., McGrath, F., Macadam, I., Jones, R., (2019). High-resolution climate projections for South Asia to inform climate impacts and adaptation studies in the GangesBrahmaputra-Meghna and Mahanadi deltas. Sci. Total Environ. 650, 1499-1520. doi:10.1016/j.scitotenv.2018.08.376

Jin, L., Whitehead, P.G., Rodda, H., Macadam, I., Sarkar, S., (2018a). Simulating climate change and socio-economic change impacts on flows and water quality in the Mahanadi River system, India. Sci. Total Environ. 637-638, 907-917. doi:10.1016/j.scitotenv.2018.04.349

Jin, L., P.G. Whitehead, K. Appeaning Addo, B. Amisigo, I. Macadam, T. Janes, J. Crossman, R.J. Nicholls, M. McCartney and H.J.E. Rodda, (2018b). Modeling future flows of the Volta River system: Impacts of climate change and socio-economic changes. Science of the Total Environment, 637-638, 1069-1080.

Jin, L., Whitehead, P.G., Sarkar, S., Sinha, R., Futter, M.N., Butterfield, D., Caesar, J., Crossman, J., (2015). Assessing the impacts of climate change and socio-economic changes on flow and phosphorus flux in the Ganga river system. Environ. Sci. Process. Impacts 17, 1098-1110. doi:10.1039/C5EM00092K

Jones, R.G., Noguer, M., Hassell, D.C., Hudson, D., Wilson, S.S., Jenkins, G.J., Mitchell, J.F.B., (2004). Generating high resolution climate change scenarios using PRECIS, Met Office Hadley Centre, Exeter, UK.

Kebede, A.S., Nicholls, R.J., Allan, A., Arto, I., Cazcarro, I., Fernandes, J.A., Hill, C.T., Hutton, C.W., Kay, S., Lázár, A.N., Macadam, I., Palmer, M., Suckall, N., Tompkins, E.L., Vincent, K., Whitehead, P.W., (2018). Applying the global RCP-SSP-SPA scenario framework at sub-national scale: A multi-scale and participatory scenario approach. Sci. Total Environ. 635, 659-672. doi:10.1016/j.scitotenv.2018.03.368

Kondolf, G.M., Rubin, Z.K., and Minear, J.T., 2014, Dams on the Mekong: Cumulative sediment starvation: Water Resources Research, v. 50, p. 5158-5169.

Lee, S.K. \& Dang, T.A. (2018) Paddy Water Environ. 16, 63, PP 1-10 https://doi.org/10.1007/s10333-018-0681-8

Lu, X. X., Li, S., Kummu, M., Padawangi, R., \& Wang, J. J. (2014). Observed changes in the 
water flow at Chiang Saen in the lower Mekong: Impacts of Chinese dams? Quaternary International, 336, 145-157. https://doi.org/10.1016/j.quaint.2014.02.006

Mekong River Commission, (2010). IWRM-based Basin Development Strategy for the Lower Mekong Basin. Fourth draft. Mekong River Commission. MRC. 2010b. The Mekong Ricer Commission. (Available at: http://www.mrcmekong.org/. Accessed on 16/12/2010). United Nations Environment Programme. Afte.

Mekong River Commission, (2009). Initiative on sustainable hydropower work plan. Mekong River Commission.(Available at: http:// www.mrcmekong.org/programmes/hydropower/hydropower-pub.htm. Accessed on: 17/12/2010).

Nash, J.E., Sutcliffe, J.V., (1970). River flow forecasting through conceptual models - Part 1 A discussion of principles. J. Hydrol. 10, 282-290. doi:10.1016/0022-1694(70)90255-6

Nicholls, R.J., Hutton, C.W., Lázár, A.N., Allan, A., Adger, W.N., Adams, H., Wolf, J., Rahman, M., Salehin, M., (2016). Integrated assessment of social and environmental sustainability dynamics in the Ganges-Brahmaputra-Meghna delta, Bangladesh. Estuar. Coast. Shelf Sci. 183, 370-381. doi:10.1016/j.ecss.2016.08.017

Nicholls, R.J., Whitehead, P.G., Wolf, J., Rahman, M., Salehin, M., (2015). The GangesBrahmaputra-Meghna delta system: biophysical models to support analysis of ecosystem services and poverty alleviation. Environ. Sci. Process. Impacts 17, 10161017. doi:10.1039/C5EM90022K

Nicholls, R.J., Brown, S., Goodwin, P., Wahl, T., Lowe, J., Solan, M., Godbold, J.A., Haigh, I.D., Lincke, D., Hinkel, J., Wolff, C., Merkens, J., (2018). Stabilization of global temperature at $1.5^{\circ} \mathrm{C}$ and $2.0^{\circ} \mathrm{C}$ : implications for coastal areas 376 Philosophical Transactions of the Royal Society A: Mathematical, Physical and Engineering Sciences, 376, 20160448.

Pathak D., Whitehead P G , Futter M N and Sinha R , (2018). Water quality assessment and catchment-scale nutrient flux modeling in the Ramganga River Basin in North India: An application of INCA model. Science of the Total Environment, Volumes 631-632, 201215

Rankinen, K., Karvonen, T., Butterfield, D., (2006). An application of the GLUE methodology for estimating the parameters of the INCA N model. Science of the total environment, 365(1): 123-139.

Smajgl, A., Toan, T. Q., Nhan, D. K., Ward, J., Nguyễn Hiếu Trung, Lê Quang Trí, Phạm Thanh Vũ. (2015). Responding to rising sea levels in the Mekong Delta. Nature Climate Change, 5, 167-174. Retrieved from http://dx.doi.org/10.1038/nclimate2469

Spear RC and Hornberger GM, (1980). Eutrophication in the Peel Inlet II. Identification of critical uncertainties via generalised sensitivity analysis. Water Research 1980;14:43 49.

Thuc, T, N V Thang, H T L Huong, M V Khiem, N X Hien, D H Phong, (2016). Climate Change And Sea Level Rise Scenarios for Vietnam, Technical Summary for Policymakers, Report to Ministry of Natural Resources \& Environment, Vietnam Institute Of Meteorology, Hydrology And Climate Change Hanoi, Vietnam, 39p

Vörösmarty, C.J., McIntyre, P.B., Gessner, M.O., Dudgeon, D., Prusevich, A., Green, P., Glidden, S., Bunn, S.E., Sullivan, C.A., Liermann, C.R., Davies, P.M., (2010). Global threats to human water security and river biodiversity. Nature $467,555-561$. doi:10.1038/nature09440 
Wade, A.J., Butterfield, D., Lawrence, D.S., Bärlund, I., Ekholm, P., Lepistö, A., Yli-Halla, M., Rankinen, K., Granlund, K., Durand, P., Kaste, Ø., (2009). The Integrated Catchment Model of Phosphorus (INCA-P), a new structure to simulate particulate and soluble phosphorus transport in European catchments, Deliverable 185 to the EU Euro-limpacs project, UCL, London.

Wade, A.J., Durand, P., Beaujouan, V., Wessel, W.., Raat, K.J., Whitehead, P.G., Butterfield, D., Rankinen, K., Lepisto, A., (2002a). A nitrogen model for European catchments: INCA, new model structure and equations. Hydrol. Earth Syst. Sci. 6, 559582. doi:10.5194/hess-6-559-2002

Wade, A.J., Whitehead, P.G., Butterfield, D., (2002b). The Integrated Catchments model of Phosphorus dynamics (INCA-P), a new approach for multiple source assessment in heterogeneous river systems: model structure and equations. Hydrol. Earth Syst. Sci. doi:10.5194/hess-6-583-2002

Whitehead, P.G., (1990). Modelling nitrate from agriculture into public water supplies. Philos. Trans. R. Soc. London. Ser. B Biol. Sci. 329, 403-410. doi:10.1098/rstb.1990.0182

Whitehead, P.G., Wilson, E., Butterfield, D., (1998a). A semi-distributed integrated nitrogen model for multiple source assessment in catchments (INCA): Part I - model structure and process equations. Sci. Total Environ. 210-211, 547-558. doi:10.1016/S00489697(98)00037-0

Whitehead, P.G., Wilson, E., Butterfield, D., Seed, K., (1998b). A semi-distributed integrated flow and nitrogen model for multiple source assessment in catchments (INCA): Part II - application to large river basins in south Wales and eastern England. Sci. Total Environ. 210-211, 559-583. doi:10.1016/S0048-9697(98)00038-2

Whitehead, P.G., Barbour, E., Futter, M.N., Sarkar, S., Rodda, H., Caesar, J., Butterfield, D., Jin, L., Sinha, R., Nicholls, R., Salehin, M., (2015a). Impacts of climate change and socio-economic scenarios on flow and water quality of the Ganges, Brahmaputra and Meghna (GBM) river systems: low flow and flood statistics. Environ. Sci. Process. Impacts 17, 1057-1069. doi:10.1039/c4em00619d

Whitehead, P.G., Bussi, G., Hossain, M.A., Dolk, M., Das, P., Comber, S., Peters, R., Charles, K.J., Hope, R., Hossain, S., (2018a). Restoring water quality in the polluted Turag-Tongi-Balu river system, Dhaka: Modelling nutrient and total coliform intervention strategies. Sci. Total Environ. 631-632. doi:10.1016/j.scitotenv.2018.03.038

Whitehead, P.G., Jin, L., Macadam, I., Janes, T., Sarkar, S., Rodda, H.J.E., Sinha, R., Nicholls, R.J., (2018b). Modelling impacts of climate change and socio-economic change on the Ganga, Brahmaputra, Meghna, Hooghly and Mahanadi river systems in India and Bangladesh. Sci. Total Environ. 636, 1362-1372. doi:10.1016/j.scitotenv.2018.04.362

Whitehead, P.G., Leckie, H., Rankinen, K., Butterfield, D., Futter, M.N.N., Bussi, G., (2016). An INCA model for pathogens in rivers and catchments: Model structure, sensitivity analysis and application to the River Thames catchment, UK. Sci. Total Environ. 572, 1601-1610. doi:10.1016/j.scitotenv.2016.01.128

Whitehead, P.G., Sarkar, S., Jin, L., Futter, M.N., Caesar, J., Barbour, E., Butterfield, D., Sinha, R., Nicholls, R., Hutton, C., Leckie, H.D., (2015b). Dynamic modeling of the Ganga river system: impacts of future climate and socio-economic change on flows and nitrogen fluxes in India and Bangladesh. Environ. Sci. Process. Impacts 17, 10821097. doi:10.1039/C4EM00616J

Xue, Z., He, R., Liu, J. P., and Warner, J. C. (2012). Modeling transport and deposition of the Mekong River sediment. Continental Shelf Research, 37(0), 66-78. 
781 https://doi.org/http://dx.doi.org/10.1016/j.csr.2012.02.010

782 Young, P., (2003). Top-down and data-based mechanistic modelling of rainfall-flow 783 dynamics at the catchment scale. Hydrol. Process. 17, 2195-2217.

784 doi:10.1002/hyp.1328 